\title{
L-Tryptophan Challenge and Cognitive Deficits in Bipolar Disorder: Evidence for Hyperserotonergic and Hypodopaminergic Mechanisms
}

\author{
Pradeep J Nathan*,' and Ben J Harrison' \\ 'Neuropsychopharmacology Laboratory, Brain Sciences Institute, Swinburne University of Technology, Victoria, Australia
}

Neuropsychopharmacology (2003) 28, 2212 -22I3, advance online publication, 30 July 2003; doi: I 0. I 038/sj.npp. I 300269

Sir

Dr Sobczak et al reported that intravenous L-tryptophan (L-Trp) in first-degree relatives of patients with bipolar disorder (BD) leads to cognitive deficits in executive function and attention compared to healthy control subjects. The authors suggest that impairment in these domains may reflect a central vulnerability of the serotonergic system in frontal brain regions and possible involvement in the cognitive sequelae of $\mathrm{BD}$. The authors also report that in $\mathrm{BD}$ relatives and controls, $\mathrm{L}-\mathrm{Trp}$ impaired delayed memory performance and psychomotor function. For the former group, L-Trp appears to have impaired memory due to a disruption in learning and/or memory consolidation, while for the control group their learning ability was unaffected.

An important consideration with regard to neurochemical specificity is whether the cognitive deficits in $\mathrm{BD}$ relatives are entirely attributable to an enhanced serotonergic function following L-Trp. It is well known that large neutral amino acids such as tryptophan, tyrosine and phenylalanine compete for the same blood-brain barrier transporter. A number of studies have shown that infusion of L-Trp can reduce the ratio of tyrosine to large neutral amino acids (Heuther et al, 1992), biochemical markers of dopamine synthesis (Hashiguti et al, 1993), and dopaminergic behavioral responses (Molina et al, 2001). It is therefore possible that the impairments in cognitive function following L-Trp may be partially explained by an indirect effect on reducing central dopamine turnover. Further, dopamine has been shown to modulate neuroendocrine responses such as prolactin and growth hormone release (Lal, 1988) and

\footnotetext{
* Correspondence: Associate Professor PJ Nathan, Neuropsychopharmacology Laboratory, Brain Sciences Institute, Swinburne University of Technology, 400 Burwood Road, Hawthorn 3122, Victoria, Australia, Fax: + 6I-3-92145525, E-mail: pnathan@bsi.swin.edu.au

Received 17 April 2003; accepted 09 June 2003

Online publication: 16 June 2003 at http://www.acnp.org/citations/ Npp061603030166/default.pdf
}

cognitive processes such as working memory (Ellis and Nathan, 2001), attention and executive function (Robbins, 2000), which are also domains affected by L-Trp infusion (Charney et al, 1982; Luciana et al, 2001; Sobczak et al, 2003). This suggests that the physiological and behavioral effects of L-Trp administration in first-degree BD relatives may be mediated by both serotonergic and dopaminergic mechanisms.

Independent of $\mathrm{L}-\mathrm{Trp}$ infusion, the $\mathrm{BD}$ relatives showed deficits in memory, attention, and psychomotor function compared to controls to which the authors suggest may represent cognitive-trait marker of this illness. It is also evident that the cognitive deficit and clinical symptoms of $\mathrm{BD}$ are mediated in part by abnormalities of the mesocortical dopamine system. For example, patients with BD show primary deficits in executive function, such as planning, problem solving, abstract concept formation, set-shifting, and working memory (Quraishi and Frangou, 2002), which have been linked to the neuromodulatory influence of mesocortical dopamine activity. Supporting this link, recent studies have reported an improvement in acute manic symptoms following dopamine precursor depletion (McTavish et al, 2001; Scarna et al, 2003), while tryptophan depletion has been demonstrated to have no significant effects on cognitive symptoms in euthymic BD patients (Hughes et al, 2002).

While the study by Sobczak et al (2003) is an important finding showing cognitive deficits following L-Trp infusion in first-degree relatives of BD patients, further studies are needed to determine if the effects are entirely attributable to enhancement of serotonergic function, as it is likely that dopaminergic mechanisms may in part be responsible for some of the cognitive deficits associated with this challenge.

\section{REFERENCES}

Charney DS, Heninger GR, Reinhard JF, Sternberg DE, Hafstead KM (1982). The effect of IV L-tryptophan on prolactin, growth 
hormone and mood in healthy subjects. Psychopharmacology 78: $38-43$.

Ellis KA, Nathan PJ (2001). The pharmacology of human working memory. Int J Neuropsychopharmacol 4: 299-313.

Hashiguti H, Nakahara D, Maruyama W, Naoi M, Ikeda T (1993). Simultaneous determination of in vivo hydroxylation of tyrosine and tryptophan in rat striatum by microdialysis-HPLC: relationship between dopamine and serotonin biosynthesis. J Neural Transm Gen Sect 93: 213-223.

Heuther G, Hajak G, Reimer A, Poeggeler B, Blomer M, Rodenbeck A, Ruther E (1992). The metabolic fate of infused L-tryptophan in men: possible clinical implications of the accumulation of circulating tryptophan and tryptophan metabolites. Psychopharmacology 109: 422-432.

Hughes JH, Gallagher P, Young AH (2002). Effects of acute tryptophan depletion on cognitive function in euthymic bipolar patients. Eur Neuropsychopharmacol 12: 123-128.

Lal S (1988). Apomorphine in the evaluation of dopaminergic function in man. Prog Neuropsychopharmacol Biol Psychiatry 12: 117-164.

Luciana M, Burgund ED, Berman M, Hanson KL (2001). Effects of tryptophan loading on verbal, spatial and affective work- ing memory in healthy adults. $J$ Psychopharmacol 15: 21-230.

McTavish SFB, McPherson MH, Harmer CJ, Clark L, Sharp T, Goodwin GM, Cowen PJ (2001). Antidopaminergic effects of dietary tyrosine depletion in healthy subjects and patients with manic illness. Br J Psychiatry 179: 356-360.

Molina PE, Ahmed N, Gatley J, Volkow ND, Abumrad NN (2001). L-Tryptophan attenuation of the dopaminergic and behavioral responses to cocaine. Life Sci 69: 1897-1906.

Quraishi S, Frangou S (2002). Neuropsychology of bipolar disorder: a review. J Affect Disord 72: 209-226.

Robbins TW (2000). Chemical neuromodulation of frontalexecutive functions in humans and other animals. Exp Brain Res 133: 130-138.

Scarna A, Gijsman HJ, McTavish SF, Harmer CJ, Cowen PJ, Goodwin GM (2003). Effects of a branched-chain amino acid drink in mania. Br J Psychiatry 182: 210-213.

Sobczak S, Honig A, Schmitt JAJ, Reidel WJ (2003). Pronounced cognitive deficits following an intravenous L-tryptophan challenge in first-degree relatives of bipolar patients compared to healthy controls. Neuropsychopharmacology 28: 711-719. 